\title{
Structure of the Catalytically Active Copper-Ceria Interfacial Perimeter
}

\author{
Aling Chen, ${ }^{1 \dagger}$ Xiaojuan Yu, ${ }^{2 \dagger}$ Yan Zhou, ${ }^{1 *}$ Shu Miao, ${ }^{1}$ Yong $L i,{ }^{1}$ Sebastian Kuld, ${ }^{3}$ Jens Sehested, ${ }^{3 *}$ \\ Jingyue Liu, ${ }^{4}$ Toshihiro Aoki, ${ }^{5}$ Song Hong, ${ }^{6}$ Matteo Farnesi Camellone, ${ }^{7}$ Stefano Fabris, ${ }^{7}$ Jing Ning, ${ }^{1}$ \\ Chuanchuan Jin, ${ }^{1}$ Chengwu Yang, ${ }^{2}$ Alexei Nefedov, ${ }^{2}$ Christof Wöll, ${ }^{2}$ Yuemin Wang, ${ }^{2 *}$ Wenjie Shen ${ }^{1 *}$
}

${ }^{1}$ State Key Laboratory of Catalysis, Dalian Institute of Chemical Physics, Chinese Academy of Sciences, Dalian 116023, China.

${ }^{2}$ Institute of Functional Interfaces, Karlsruhe Institute of Technology, Eggenstein-Leopoldshafen 76344, Germany.

${ }^{3}$ Haldor Topsøe A/S, Haldor Topsøes Allé 1, DK-2800 Kgs. Lyngby, Denmark.

${ }^{4}$ Department of Physics, Arizona State University, Tempe, Arizona 85287, USA.

${ }^{5}$ LeRoy Eyring Center for Solid State Science, Arizona State University, Tempe, Arizona 85287, USA.

${ }^{6}$ Center for Instrumental Analysis, Beijing University of Chemical Technology, Beijing 100029, China.

${ }^{7}$ Istituto Officina dei Materiali, Consiglio Nazionale delle Ricerche CNR-IOM, I-34149 Trieste, Italy.

TThese authors contributed equally to this work.

*To whom correspondence should be addressed.

E-mail: zhouyan@dicp.ac.cn; jss@topsoe.dk; yuemin.wang@kit.edu; shen98@dicp.ac.cn 


\begin{abstract}
$\mathrm{Cu} / \mathrm{CeO}_{2}$ catalysts are highly active for the low-temperature water-gas shift-a core reaction in syngas chemistry for tuning $\mathrm{H}_{2} / \mathrm{CO} / \mathrm{CO}_{2}$ proportions in feed-streams-but direct identification and a quantitative description of the active sites remains challenging. Here, we report that the active copper clusters consist of a bottom layer of mainly $\mathrm{Cu}^{+}$atoms bonded on the oxygen vacancies of ceria, in a form of $\mathrm{Cu}^{+}-\mathrm{O}_{v}-\mathrm{Ce}^{3+}$, and a top layer of $\mathrm{Cu}^{0}$ atoms coordinated with the underlying $\mathrm{Cu}^{+}$ atoms. This atomic structure model is based on directly observing copper clusters dispersed on ceria by a combination of scanning transmission electron microscopy and electron energy loss spectroscopy, in situ probing the interfacial copper-ceria bonding environment by infrared spectroscopy, and rationalization by density functional theory calculations. These results, together with reaction kinetics, reveal that the reaction occurs at the copper-ceria interfacial perimeter via a site cooperation mechanism: the $\mathrm{Cu}^{+}$site chemically adsorbs $\mathrm{CO}$ while the neighboring $-\mathrm{O}_{v}-\mathrm{Ce}^{3+}$ site dissociatively activates $\mathrm{H}_{2} \mathrm{O}$.
\end{abstract}

Copper nanoparticles, dispersed on ceria, constitute a highly efficient catalyst system for reactions in syngas (a mixture of $\mathrm{H}_{2}, \mathrm{CO}$, and $\mathrm{CO}_{2}$ ) chemistry, such as the low-temperature water-gas shift (WGS) reaction ${ }^{1-7}$ and $\mathrm{CO} / \mathrm{CO}_{2}$ hydrogenation yielding methano ${ }^{8-13}$. In these technologically highly relevant $\mathrm{Cu} / \mathrm{CeO}_{2}$ catalysts, copper is commonly viewed as the active component, while the ceria support, with a prominent redox behavior, tunes the dispersion and chemical state of the copper nanoparticles via strong metal-support interactions ${ }^{14-16}$. In the case of the low-temperature WGS, a crucial reaction for regulating the $\mathrm{H}_{2} / \mathrm{CO}^{-} \mathrm{CO}_{2}$ proportions in feed gases for the downstream industrial applications, the active sites have been presumably proposed to locate at the copper-ceria interface. This hypothesis is based on intensive experimental studies on both real $\mathrm{Cu} / \mathrm{CeO}_{2}$ catalysts ${ }^{2-6}$ and model $\mathrm{CeO}_{2} / \mathrm{Cu}$ systems $^{17,18}$ as well as theoretical simulations of copper-ceria interactions ${ }^{19-23}$. A direct experimental verification of the geometric and electronic structures of the copper-ceria interface at atomic scale, however, together with a quantitative description of the active sites for the activation of $\mathrm{CO}$ and $\mathrm{H}_{2} \mathrm{O}$ molecules during the low-temperature WGS reaction on the $\mathrm{Cu} / \mathrm{CeO}_{2}$ catalysts, has not yet been obtained. 
The vital role of the metal-support interfaces in ceria-supported precious metal (mostly $\mathrm{Au}$ and $\mathrm{Pt}$ ) nanoparticles in catalysis has been well demonstrated in a convincing fashion, in which the size/shape of ceria determines the structure of the metal-support interfaces and maintains the metal particles by strong metal-support bonding ${ }^{24-30}$. However, such detailed information on the chemical nature of the metal-support interface in the $\mathrm{Cu} / \mathrm{CeO}_{2}$ system is rare. This lack of data for $\mathrm{Cu}$, a much cheaper metal, primarily results from the difficulties in precisely controlling the size of copper nanoparticles on ceria and directly identifying the copper-ceria interfacial structures at atomic scale. The strong copper-ceria interaction for constructing the metal-support interface proceeds via a unique pattern, which largely differs from the case of precious metals on the same substrate, ceria. Unlike $\mathrm{Au}$ and $\mathrm{Pt}$ nanoparticles that form well-defined crystalline structures on ceria ${ }^{27-30}$, copper locates mainly at the step edges, instead of the terraces, on reduced ceria surfaces ${ }^{21}$, forming irregular, small clusters that are very difficult to be imaged by electron microscopy because of the much lower degree of crystallinity and the rather poor contrast between copper and cerium ${ }^{5}$. Here, we present experimental evidence for the atomic structure of the catalytically active copper-ceria interfacial perimeter via a combined microscopic and spectroscopic study on the evolution of ultrafine copper clusters $(<1.5 \mathrm{~nm})$ on a rod-shaped ceria under reactive gases and at elevated temperatures. The atomic configurations of the copper clusters and the copper-ceria interfaces were directly observed using a combination of aberration-corrected scanning transmission electron microscopy (AC-STEM) and electron energy loss spectroscopy (EELS). The chemical binding environments of the interfacial copper atoms were probed by in situ infrared (IR) spectroscopy, while density functional theory (DFT) calculations provided complementary insights into the interfacial charge transfer and the atomic bonding pattern. Accordingly, the atomic structure of the active sites, which locate at the copper-ceria interfacial perimeter, for the low-temperature WGS reaction, has been unambiguously identified and quantitatively described.

\section{Results}

Geometric structure of copper clusters on ceria. We started with the deposition of copper oxide on a rod-shaped ceria support ${ }^{31}$, yielding the $\mathrm{CuO} / \mathrm{CeO}_{2}$ precursor (Supplementary Fig. 
1 and Table 1). Detailed structural analysis, using a combination of STEM/EELS, found that $\mathrm{CuO}$ clusters of $1.3 \mathrm{~nm}$ dominantly located on $\mathrm{CeO}_{2}(111)$ while smaller $\mathrm{CuO}$ clusters $(<1.0$ $\mathrm{nm}$ ) mainly populated on $\mathrm{CeO}_{2}(100)$, showing a stronger interaction between copper oxides and the (100) facet of ceria (Supplementary Fig. 2). The average thickness of these clusters was $0.54 \mathrm{~nm}$, which approximately equaled to a bilayer configuration of copper atoms. In addition, tiny domains and monolayers, containing only few to tens of copper atoms, were also observed to preferentially locate at the step-defects of ceria rods. Temperatureprogrammed reduction of the $\mathrm{CuO} / \mathrm{CeO}_{2}$ precursor with hydrogen confirmed that copper oxides presented as finely dispersed $\mathrm{CuO}$ and surface-substituted $\mathrm{Cu}-\mathrm{O}_{\mathrm{x}}-\mathrm{Ce}$ solid solution (Supplementary Fig. 3). Their reductions occurred mainly at the temperature range of 383$493 \mathrm{~K}$; the $\mathrm{CuO}$ phase was easily reduced into metallic copper species, which promoted the subsequent reductions of the $\mathrm{Cu}-\mathrm{O}_{\mathrm{x}}$-Ce phase and the surface oxygen on ceria via a hydrogen spillover effect ${ }^{32,33}$. Accordingly, the $\mathrm{Cu} / \mathrm{CeO}_{2}$ catalysts were obtained by hydrogen reduction of the $\mathrm{CuO} / \mathrm{CeO}_{2}$ precursor at temperatures varying from 473 to $773 \mathrm{~K}$ for mediating the copper-ceria interfacial structure, and labeled as $\mathrm{Cu}-\mathrm{T}$, where $\mathrm{T}$ refers to the temperature during hydrogen treatment.

The copper-ceria interfaces in the CU-T catalysts were examined by STEM/EELS. On the Cu-473 sample, plate-shaped copper clusters were observed on the ceria surface, with a mean width of $\sim 1.0 \mathrm{~nm}$ and an average thickness of $\sim 0.40 \mathrm{~nm}$ (Fig. 1a,b and Supplementary Fig. $4 a, b)$. EELS of $C u L_{2,3}$ and $C e M_{4,5}$ edges unambiguously affirmed that the copper clusters anchored on ceria rods (Fig. 1c). Since the relative intensity ratios of the $\mathrm{Ce}_{4,5}$ edges are 1.31 for $\mathrm{Ce}^{3+}$ and 0.91 for $\mathrm{Ce}^{4+}$ in ceria ${ }^{34}$, the $\mathrm{I}_{\mathrm{M} 5} / \mathrm{I}_{\mathrm{M} 4}$ ratios (1.15-1.18) in Fig. $1 \mathrm{c}$ indicated the presence of a mixture of $\mathrm{Ce}^{3+}$ and $\mathrm{Ce}^{4+}$ around the $\mathrm{Cu}$ clusters. Line-scanning EELS of $\mathrm{Cu} \mathrm{L}_{2,3}$ edges crossing an individual copper cluster identified the spatial distribution from the top edge of the cluster to the copper-ceria interface (Supplementary Fig. 4c). Judged from the

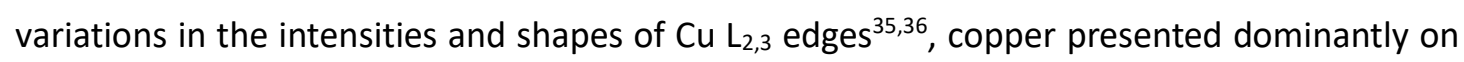
the cluster and at the $\mathrm{Cu}-\mathrm{CeO}_{2}$ interface, consisting of metallic and partially oxidized species. Atom-resolved high-angle annular dark-field (HAADF) STEM images further identified the arrangements of copper atoms within the clusters and at the copper-ceria interfaces (Fig. $1 d$,e and Supplementary Fig. 4d-f). Most copper clusters had a geometric configuration of 
approximately two-atom layers, while copper domains and monolayers, containing few to tens of atoms, were also observed occasionally. The dominant bilayers preferentially anchored on the defect sites at the step edges along ceria rods; the average distance of the adjoining copper atomic columns on the top layer was $0.22 \mathrm{~nm}$ while the distance between the two copper layers was $0.18 \mathrm{~nm}$ (Fig. 1e), which are equal to the values in faceted copper crystals $(0.18 \mathrm{~nm} \text { for } \mathrm{Cu}(200) \text { and } 0.22 \mathrm{~nm} \text { for } \mathrm{Cu}(111))^{36}$. The distance between the top layer of cerium atoms and the copper atomic layer was $0.28 \mathrm{~nm}$, indicating that the two metals are connected via interfacial oxygen atoms that are invisible in HAADF.

The copper cluster sizes slightly increased as the temperature during hydrogen reduction of the $\mathrm{CuO} / \mathrm{CeO}_{2}$ precursor increased. On the $\mathrm{Cu}-573$ catalyst, $\mathrm{Cu}$ clusters $1.1 \mathrm{~nm}$ wide and 0.44 $\mathrm{nm}$ thick were abundant, but smaller copper clusters were also observed (Supplementary Fig. 5a). In the case of the $\mathrm{Cu}-673$ sample, $\mathrm{Cu}$ clusters with the average width of $1.2 \mathrm{~nm}$ and the thickness of $0.45 \mathrm{~nm}$ became dominant, while smaller clusters decreased remarkably (Supplementary Fig. 5b). Line-scanning EELS crossing individual copper clusters in these samples confirmed that the copper presented as metallic on the top layers while as a mixture of metallic and positively-charged at the bottom layers that strongly bonded with $\mathrm{Ce}^{3+}$ species on the ceria surface. On the $\mathrm{Cu}-773$ catalyst, the average width and thickness of the $\mathrm{Cu}$ clusters enlarged to 1.5 and $0.46 \mathrm{~nm}$ (Fig. 2 and Supplementary Fig. 6), respectively. The copper clusters existed mainly as bilayers, with the minor presence of monolayers and trilayers. They preferentially located at the step edges along ceria rods, where defect sites are abundant due to the distortion of ceria surface. This result manifests that the strong chemical bonding of copper clusters on ceria rods effectively prohibited the growth and aggregation of the copper clusters even at temperatures up to $773 \mathrm{~K}$ and under hydrogen atmosphere in the $\mathrm{Cu} / \mathrm{CeO}_{2}$ catalysts. Based on these observations, it could be proposed that most copper clusters in the $\mathrm{Cu} / \mathrm{CeO}_{2}$ catalysts present as bilayers; the mean width of the copper clusters enlarged only slightly as increasing the temperature for hydrogen treatment while the average thickness kept approximately consistent at a bilayer geometry. According to EELS analysis, it is highly likely that the copper atoms at the top layer are in metallic state mainly while the copper atoms at the bottom layer are positively-charged and in direct contact with the oxygen vacancy $\left(\mathrm{O}_{v}\right)$ site on the ceria surface to form the copper-ceria interface. 
Chemical environment of the copper-ceria interface. The chemical states of copper in the CU-T catalysts were investigated by X-ray photoelectron spectroscopy (XPS) and chemical titrations with $\mathrm{H}_{2}$ and $\mathrm{N}_{2} \mathrm{O}$. Analysis of the CuL3VV/Cu2p XPS data evidenced the co-existence of $\mathrm{Cu}^{0}$ and $\mathrm{Cu}^{+}$species; the $\mathrm{Cu}^{+} / \mathrm{Cu}^{0}$ ratio strongly depended on the temperature during hydrogen treatment (Supplementary Fig. 7 and Table 2). On the $\mathrm{Cu}-473$ sample, both $\mathrm{Cu}^{0}$ and $\mathrm{Cu}^{+}$species were detected, but $\mathrm{Cu}^{+}$was dominant. The fraction of this positively-charged copper species gradually weakened and decayed to be a minor component on the $\mathrm{Cu}-773$ sample. Together with this, the fraction of surface $\mathrm{Ce}^{3+}$ species, which are directly related to the $\mathrm{O}_{v}$ sites, gradually increased from $27 \%$ on $\mathrm{Cu}-473$ to $36 \%$ on $\mathrm{Cu}-773$, demonstrating the continuous reduction of ceria. Chemical titrations with $\mathrm{H}_{2}$ and $\mathrm{N}_{2} \mathrm{O}$ on the $\mathrm{Cu}-\mathrm{T}$ samples determined the total numbers of $\mathrm{Cu}^{0}$ and $\mathrm{Ce}^{3+}$ species on the catalyst surface. Estimated from the amounts of consumed probe molecules (Supplementary Fig. 8 and Table 3), the total number of surface $\mathrm{Ce}^{3+}$ was about seven times greater than that of $\mathrm{Cu}^{0}$ on the $\mathrm{Cu}-473$ sample; this ratio became more significant on the $\mathrm{Cu}-773$ sample. These results firmly support that a large fraction of the catalyst surface is oxygen deficient.

The binding environments of the interfacial copper and cerium species on the $\mathrm{Cu}-\mathrm{T}$ catalysts were examined by in situ IR spectroscopy using $\mathrm{CO}$ as a probe molecule, which only interacts with the outermost surface of the sample ${ }^{37}$. Upon exposure of the $\mathrm{Cu}-473$ catalyst to $\mathrm{CO}$ at $80 \mathrm{~K}$, four distinct CO bands appeared at 2167, 2154, 2110 and $2094 \mathrm{~cm}^{-1}$ (Fig. 3a and Supplementary Fig. 9). The former two bands are characteristic for $\mathrm{CO}$ adsorbed on the ceria surface while the latter two bands are assigned to $\mathrm{CO}$ adsorption on the copper cluster. On the basis of reference data acquired for ceria single- crystal facets ${ }^{38,39}$, the $2154 \mathrm{~cm}^{-1}$ band was assigned to $\mathrm{CO}$ weakly bound to the 7-fold coordinated $\mathrm{Ce}^{4+}$ site, while the signal at 2167 $\mathrm{cm}^{-1}$ was characteristic for $\mathrm{CO}$ adsorbed more strongly at the defect sites (mainly $-\mathrm{Ce}^{3+}-\mathrm{O}_{\mathrm{v}}$ ). This assignment is further supported by the bond strength of $\mathrm{CO}$ on ceria, estimated from the temperature-dependent IR data (Fig. 3b). Upon heating the sample, the $2154 \mathrm{~cm}^{-1}$ band weakened rapidly and vanished practically at $100 \mathrm{~K}$ with a binding energy of $26 \mathrm{~kJ} / \mathrm{mol}$; while the band at $2167 \mathrm{~cm}^{-1}$ gradually shifted to $2170-2173 \mathrm{~cm}^{-1}$ and fully disappeared at above $120 \mathrm{~K}$, having a binding energy of $33 \mathrm{~kJ} / \mathrm{mol}$. These defect sites that bound CO more strongly 
include not only the reduced ceria surfaces but also the $\mathrm{Ce}^{3+}$-related sites generated via the strong interaction with Cu clusters at their interfaces.

The two intense bands at 2110 and $2094 \mathrm{~cm}^{-1}$ were ascribed to $\mathrm{CO}$ absorption on $\mathrm{Cu}^{+}$and $\mathrm{Cu}^{0}$ sites ${ }^{40-42}$, respectively. Analysis on the temperature-dependent IR spectra yielded binding energies of $76 \mathrm{~kJ} / \mathrm{mol}$ for $\mathrm{CO}-\mathrm{Cu}^{+}$and $69 \mathrm{~kJ} / \mathrm{mol}$ for $\mathrm{CO}-\mathrm{Cu}^{0}$ (Fig. 3c). The stronger binding of $\mathrm{CO}$ on the $\mathrm{Cu}^{+}$site is because the reduced electron density on $\mathrm{Cu}^{+}$enhances $\mathrm{CO} \sigma$-donation interaction ${ }^{40}$. More interestingly, the $\mathrm{Cu}^{0}$ and $\mathrm{Cu}^{+}$sites varied dynamically and reversibly in response to alternating reductive and oxidative atmospheres (Fig. 3d). The Cu-473 sample initially contained both $\mathrm{Cu}^{+}\left(2111 \mathrm{~cm}^{-1}\right)$ and $\mathrm{Cu}^{0}\left(2094 \mathrm{~cm}^{-1}\right)$ species, while a subsequent exposure to molecular oxygen at $110 \mathrm{~K}$ led to the re-oxidation of the $\mathrm{Cu}^{+} / \mathrm{Cu}^{0}$ species into $\mathrm{Cu}^{2+}\left(2181 \mathrm{~cm}^{-1}\right)$ and $\mathrm{Cu}^{+}\left(2115 \mathrm{~cm}^{-1}\right)$ species. Upon hydrogen treatment at $473 \mathrm{~K}$ again, the $\mathrm{Cu}^{+}\left(2108 \mathrm{~cm}^{-1}\right)$ and $\mathrm{Cu}^{0}\left(2090 \mathrm{~cm}^{-1}\right)$ species were fully restored. Meanwhile, a redox cycle between $\mathrm{Ce}^{4+}$ (the $\mathrm{CO}$ species being unstable at $110 \mathrm{~K}$ ) and $\mathrm{Ce}^{3+}\left(2172 \mathrm{~cm}^{-1}\right.$ ) was also identified. This strongly suggests that the copper-ceria interfacial perimeter is chemically dynamic under alternating reductive and oxidative gases, which occurs via a synergetic manner, involving the interplay between the redox circles of $\mathrm{Ce}^{4+} / \mathrm{Ce}^{3+}$ and $\mathrm{Cu}^{0} / \mathrm{Cu}^{+} / \mathrm{Cu}^{2+}$ pairs. The relative fractions of $\mathrm{Cu}^{0}$ and $\mathrm{Cu}^{+}$species on the $\mathrm{Cu}-\mathrm{T}$ catalysts were measured by $\mathrm{CO}$ adsorption at $110 \mathrm{~K}$ (Fig. 3e). Analysis on the relative intensity of the $\mathrm{Cu}^{+}-/ \mathrm{Cu}^{0}$-related IR bands verified that the $\mathrm{Cu}^{+}$site was dominant on the $\mathrm{Cu}-473$ sample but decreased to a minor site on the $\mathrm{Cu}-773$ sample. That is, the proportion of $\mathrm{Cu}^{0}$ increased at the expense of decreasing $\mathrm{Cu}^{+}$, due to the enlargement of copper clusters, as increasing the temperature for hydrogen treatment. Simultaneously, the $\mathrm{Ce}^{3+}$-related band at $2169-2172 \mathrm{~cm}^{-1}$ intensified considerably, evidencing the continuous generation of surface $\mathrm{Ce}^{3+}-\mathrm{O}_{v}$ sites via ceria reduction.

Atomic structure of the copper-ceria interfacial perimeter. According to these microscopic and spectroscopic evidences, the atomic structure of the $\mathrm{Cu}-\mathrm{CeO}_{2}$ interfacial perimeter can be described as follows. $\mathrm{CuO}$ and surface-substituted $\mathrm{Cu}-\mathrm{O}_{\mathrm{x}}-\mathrm{Ce}$ solid solution in the $\mathrm{CuO} /$ $\mathrm{CeO}_{2}$ precursor were readily reduced by hydrogen at $473 \mathrm{~K}$ into copper clusters, mostly in a bilayer geometry, forming the initial copper-ceria interfaces. These primary, tiny copper 
clusters gradually evolved into more regular bilayers as being heated up to $773 \mathrm{~K}$ under hydrogen atmosphere. During this process, the average width of the copper clusters moderately extended from 1.0 to $1.5 \mathrm{~nm}$, but the mean thickness was limited to $0.40-0.50$ $\mathrm{nm}$, which basically equaled to a bilayer configuration. In principle, the morphology of $\mathrm{Cu}$ clusters on ceria is governed by the relative bonding strengths between $\mathrm{Cu}-\mathrm{O}-\mathrm{Ce}$ at their interface and $\mathrm{Cu}-\mathrm{Cu}$ in the copper cluster, strongly depending on the temperature under hydrogen atmosphere. Theoretical investigations on the growth of copper atoms/clusters on reduced ceria surfaces have verified that the Cu-O-Ce interfacial interaction is energetically comparable to the $\mathrm{Cu}-\mathrm{Cu}$ intracluster interaction; the competition between them determines the morphology of $\mathrm{Cu}$ clusters ${ }^{19,20}$. The strong binding between copper and the reduced ceria surface, especially on the defect sites, was addressed both experimentally and theoretically with regards to the reduction degree of the ceria surface and the copper coverage ${ }^{21,22,43}$. On one hand, the $\mathrm{Cu}-\mathrm{Cu}$ intracluster interaction, i.e. the driving force for the migration and aggregation of copper clusters, enhanced as increasing the temperature; but on the other hand, the strength of the $\mathrm{Cu}-\mathrm{O}-\mathrm{Ce}$ bonding between the bottom layer atoms of the copper cluster and the $\mathrm{Ce}^{3+}-\mathrm{O}_{v}$ sites on the ceria surface increased as well, primarily because of the deep reduction of ceria. This strong interfacial bonding inhibited the detachment of copper clusters from their anchoring sites, maintaining the bilayer geometry. As confirmed by IR and XPS measurements, there were two types of copper species $\left(\mathrm{Cu}^{0}\right.$ and $\left.\mathrm{Cu}^{+}\right)$on the $\mathrm{Cu}-\mathrm{T}$ samples. Together with the direct identification of the dominant bilayer geometry by STEM analysis, the copper cluster could be proposed to consist of metallic and positively- charged copper atoms: the bottom layer contains mainly $\mathrm{Cu}^{+}$atoms that are chemically bonded with the $\mathrm{Ce}^{3+}-\mathrm{O}_{v}$ sites on the ceria surface while the top layer consists predominantly of $\mathrm{Cu}^{0}$ atoms that are in direct contact with the underlying $\mathrm{Cu}^{+}$atoms (Fig. 4a). The copper- ceria interface is formed via a chemical bonding between the positively-charged copper atoms and the surface defect sites on ceria, most likely in a form of $\mathrm{Cu}^{+}-\mathrm{O}_{v}-\mathrm{Ce}^{3+}$. Therefore, the electronic and geometric configurations of the copper-ceria interface could be viewed as the thermodynamic and kinetic balance between the copper-ceria interaction at their interface and the copper-copper interaction within the copper cluster. The bottom copper layer is 
constructed mainly via the strong electronic metal-support interaction, involving significant charge transfer from copper to ceria ${ }^{19}$, while the top copper layer is the consequence of the strong intracluster copper-copper bonding. Chemically, the copper monolayers and domains, presenting as the minor forms, could be viewed to share a similar bonding environment $\left(\mathrm{Cu}^{+}-\mathrm{O}_{v}-\mathrm{Ce}^{3+}\right)$ as the interfacial perimeter sites in the copper bilayers.

Density functional theory (DFT) simulations provide in-depth insights in the atomic structure of the copper-ceria interface and in the electronic interaction between copper atoms at the bottom layer and the reduced ceria surface. The copper-ceria interface was modelled by a periodic supercell comprising a copper (111) bilayer supported by the hydrogen-reduced ceria (111) surface $^{19}$. To reproduce the reduced ceria surface, the oxide-support was modelled with 9 atomic layers (i.e. 3 O-Ce-O layers) and included surface $\mathrm{O}$ vacancies with a 0.25 monolayer coverage ${ }^{44}$. Fig. $4 \mathrm{~b}$ displays the fully-relaxed equilibrium geometry of the copper-ceria interface, which provides evidence for the large out-of-plane structural distortions in the copper bilayer induced by the interaction with the ceria substrate. The calculated distance between the surface Ce layer and the bottom Cu layer was $0.30 \mathrm{~nm}$, in good agreement with the value of $0.28 \mathrm{~nm}$ as determined by STEM (Fig. 1e) and confirming that $O$ atoms mediated the copper-ceria bonding (Supplementary Fig. 10 and Table 4). Fig. 4c shows the plane-integrated interfacial bonding charge, which was calculated on the basis of the self-consistent ground state electron density. It clearly demonstrates the strong chemical bonding between the reduced ceria surface and the $\mathrm{Cu}$ bilayer via significant charge transfer. Analysis on the Bader charges reveals that the interfacial charge transfer involves only the $\mathrm{Cu}$ atoms at the interface and the first $\left(\mathrm{O}, \mathrm{O}_{\mathrm{v}}\right)$-Ce-O trilayer of the ceria substrate (Supplementary Fig. 11 and Table 5). On the basis of the reduced $\mathrm{Ce}^{3+}$ ions, it is estimated that 0.2-0.3 electrons per interfacial $\mathrm{Cu}$ atom are transferred from the $\mathrm{Cu}$ layer to the ceria substrate ${ }^{45}$, leading to a slightly positively-charged $\mathrm{Cu}$ layer and to a full reduction of the ceria trilayer in direct contact with the Cu bilayer. In contrast, the top Cu layer in the copper cluster is little affected by the interfacial charge transfer and remains metallic. That is, this electron depletion of the interfacial $\mathrm{Cu}$ atoms modifies their chemical state towards $\mathrm{Cu}^{+}$. This is in line with previous theoretical works on the interaction of $\mathrm{Cu}$ adatoms with ceria surfaces and particles, which have addressed different ceria surfaces and predicted the same charge transfer from the supported $\mathrm{Cu}$ atoms to the substrates, formation of $\mathrm{Cu}^{+}$species and reduction of interfacial Ce ions ${ }^{19,23,46,47}$. Overall, these results evidence the partially oxidized $\mathrm{Cu}$ species at the interface and predict the coexistence of metallic and cationic species in the 
copper bilayer, and thus solidly support the experimental interpretations of EELS, XPS and IR data.

Active sites for the water-gas shift reaction. In a subsequent set of experiments, the $\mathrm{Cu}-\mathrm{T}$ catalysts were tested for the low-temperature WGS reaction. The conversion of CO was 50\% over the $\mathrm{Cu}-473$ catalyst, and it lowered to $35 \%$ on the $\mathrm{Cu}-773$ catalyst (Supplementary Fig. 12). This activity order is generally in line with the change in the mean sizes of the copper clusters in the $\mathrm{Cu}-\mathrm{T}$ catalysts. More specifically, the reaction rate, measured at a differential reactor condition, was $1.47 \times 10^{-4} \mathrm{~mol}_{\mathrm{co}} \mathrm{g}_{\mathrm{cu}}{ }^{-1} \mathrm{~s}^{-1}$ on the $\mathrm{Cu}-473$ catalyst, and gradually declined to $9.50 \times 10^{-5}$ molco $\mathrm{cu}^{-1} \mathrm{~s}^{-1}$ on the Cu-773 catalyst (Fig. 5a). This is in consistent with the decrease in the total length of the copper-ceria interfacial perimeter, estimated from the average sizes of the copper clusters in the respect $\mathrm{Cu} / \mathrm{CeO}_{2}$ catalysts as determined by STEM analysis. This result suggests that the active sites must be located at the copperceria interfaces. Based on the atomic model of the copper-ceria interfacial perimeter (Fig. 4a), a further correlation between the reaction rate and the number of the perimeter $\mathrm{Cu}^{+}$atom yielded very close turnover frequencies $\left(2.47-2.84 \times 10^{-2} \mathrm{~s}^{-1}\right.$, Supplementary Table 6), clearly indicating that the $\mathrm{Cu}^{+}$atoms at the interfacial perimeter are intimately associated with the intrinsic activity of the $\mathrm{Cu} / \mathrm{CeO}_{2}$ catalysts.

To date, two major reaction mechanisms were proposed for the low-temperature WGS on $\mathrm{Cu} / \mathrm{CeO}_{2}$ catalysts: the redox and the formate pathways ${ }^{7,17,48-50}$. The former refers to $\mathrm{CO}$ adsorption on copper and oxidization by an $\mathrm{O}$ atom of ceria, followed by re-oxidation of the oxide-support by water; while the latter involves $\mathrm{CO}$ adsorption on copper and reaction with surface $\mathrm{OH}$ groups on ceria, followed by the decomposition of the intermediate (formate) to $\mathrm{H}_{2}$ and $\mathrm{CO}_{2}$. The similarity between the two reaction routes is that water activation at the copper-ceria interface acts as the rate-determining step. Fig. 5b,c provide IR evidence for the synergistic effect of the copper-ceria interfacial perimeter during the activation of $\mathrm{CO}$ and water by direct identification of $\mathrm{CO}-\mathrm{Cu}^{+}$at the $\mathrm{Cu}^{+}$sites and hydroxyl species $\left(-\mathrm{O}_{v}-\mathrm{Ce}^{3+}-\mathrm{OD}\right)$ formed by the dissociative adsorption of $\mathrm{D}_{2} \mathrm{O}$ at the neighboring $-\mathrm{O}_{\mathrm{v}}-\mathrm{Ce}^{3+}$ - sites on ceria. $\mathrm{CO}$ adsorbed on $\mathrm{Cu}^{0}$ sites $\left(2092 \mathrm{~cm}^{-1}\right)$ at the top layer and on $\mathrm{Cu}^{+}$sites $\left(2110 \mathrm{~cm}^{-1}\right)$ at the bottom layer of the copper clusters, while the latter had a stronger bonding as evidenced by the temperature-dependent IR data (Fig. $3 \mathrm{C}$ ). $\mathrm{D}_{2} \mathrm{O}$ adsorption at $250 \mathrm{~K}$ led to a dominating OD band at $2693 \mathrm{~cm}^{-1}$, which was accompanied by a sharp shoulder at $2714 \mathrm{~cm}^{-1}$ and a rather 
broad feature between 2630 and $2200 \mathrm{~cm}^{-1}$ (typical for $\mathrm{H}$-bonds) ${ }^{37}$. The OD group was stable at temperatures higher than $450 \mathrm{~K}$, whereas the intensity of the two latter bands decreased gradually with increasing temperature (Supplementary Fig. 13). This finding affirms that the partial dissociation of water on the reduced ceria surfaces results in the coexistence of hydroxyl (OD) and intact water $\left(\mathrm{D}_{2} \mathrm{O}\right)$ species. The dramatic attenuation of the $-\mathrm{Ce}^{3+}-\mathrm{O}^{-}$ related CO band at $2171 \mathrm{~cm}^{-1}$, observed along with the formation of hydroxyl groups, suggests that the dissociation of water is facilitated by the $-\mathrm{Ce}^{3+}-\mathrm{O}_{v}$ sites. More importantly, the co-adsorption experiment of $\mathrm{D}_{2} \mathrm{O}$ at $250 \mathrm{~K}$ and then $\mathrm{CO}$ at $110 \mathrm{~K}$ confirmed that the dissociation of water, which occurred exclusively on the $\mathrm{Ce}^{3+}-\mathrm{O}_{v}$ sites, did not disturb the adsorption of $\mathrm{CO}$ on the $\mathrm{Cu}^{+}$sites, and vice versa. Accordingly, the copper-ceria interfacial perimeter, in a chemical environment of $\mathrm{Cu}^{+}-\mathrm{O}_{v}-\mathrm{Ce}^{3+}$, is proposed to be the active sites for the activation of $\mathrm{CO}$ and $\mathrm{H}_{2} \mathrm{O}$ during the low-temperature WGS reaction.

In summary, the microscopic and spectroscopic results have explicitly identified the geometric and electronic structures of the catalytically active copper-ceria interfacial perimeter and quantitatively described the atomic configuration of the active sites for the low-temperature WGS reaction. The copper clusters consisted of a bottom layer of mainly $\mathrm{Cu}^{+}$atoms directly bonded on the oxygen vacancies of ceria, in a form of $\mathrm{Cu}^{+}-\mathrm{O}_{v}-\mathrm{Ce}^{3+}$, and a top layer of $\mathrm{Cu}^{0}$ atoms coordinated with the underlying $\mathrm{Cu}^{+}$atoms. The width of the copper clusters increased slightly with increasing temperature for hydrogen treatment, but the thickness was almost unchanged due to the strong chemical bonding between the copper atoms on the bottom layer of the $\mathrm{Cu}$ clusters and the $\mathrm{O}_{v}$ sites on the reduced ceria surfaces. The oxygen vacancy sites also participated in the dissociative activation of water molecule, which is the rate-determining step for the low-temperature WGS reaction. This work provides a general and fundamental strategy for the rational design and precise control of the metal-support interfacial structure in oxide-supported metal nanocatalysts.

\section{Methods}

Catalyst preparation. The $\mathrm{CuO} / \mathrm{CeO}_{2}$ precursor was prepared using a deposition-precipitation method. $2.0 \mathrm{~g}$ rod-shaped $\mathrm{CeO}_{2}$ were dispersed into $10 \mathrm{~mL}$ aqueous solution containing $0.3 \mathrm{~g}$ $\mathrm{Cu}\left(\mathrm{NO}_{3}\right)_{2} \cdot 3 \mathrm{H}_{2} \mathrm{O}$ at room temperature. $40 \mathrm{~mL} 7.5 \mathrm{M} \mathrm{NaOH}$ aqueous solution was added dropwise 
into the slurry, and the mixture was heated to $353 \mathrm{~K}$ and held at that temperature for $20 \mathrm{~h}$. The solid was collected by filtration, washed thoroughly with water and ethanol, dried at $353 \mathrm{~K}$ under vacuum overnight, and calcined at $573 \mathrm{~K}$ for $3 \mathrm{~h}$ in air. The $\mathrm{Cu} / \mathrm{CeO}_{2}$ catalysts were obtained by hydrogen $\left(2.0\right.$ vol. $\left.\% \mathrm{H}_{2} / \mathrm{Ar}\right)$ reduction of the $\mathrm{CuO} / \mathrm{CeO}_{2}$ precursor at $473-773 \mathrm{~K}$ for $2 \mathrm{~h}$; they were labeled as $\mathrm{Cu}-\mathrm{T}$, where $\mathrm{T}$ refers to the temperature of hydrogen reduction. The loading of copper in the $\mathrm{Cu} / \mathrm{CeO}_{2}$ catalysts was $3.36 \mathrm{wt} . \%$.

STEM and EELS characterizations. The HAADF-STEM images and EELS spectra of the $\mathrm{Cu} / \mathrm{CeO}_{2}$ catalysts were taken on a NION STEM100 at $60 \mathrm{kV}$, which was equipped with monochromator, aberration corrector, and Gatan Enfinium spectrometer. This STEM-EELS combination allows atomic image as well as atomic chemical information, with the spatial resolution $<0.1 \mathrm{~nm}$ and the energy resolution $<15 \mathrm{meV}$. The width and the thickness of individual Cu clusters were estimated from the STEM images, based on the value of the line intensity profile across the entire cluster. The atom-resolved images of the copper clusters and the copper-ceria interfaces in the $\mathrm{Cu} / \mathrm{CeO}$ samples were recorded on a JEOL ARM200F microscope (cold-field emission) operated at $200 \mathrm{kV}$. In situ IR spectra. The IR measurements were done with a state-of-the-art ultrahigh vacuum (UHV) apparatus, combing a FTIR spectrometer (Bruker Vertex 80v) and a multi-chamber UHV system (Prevac). $200 \mathrm{mg} \mathrm{CuO} / \mathrm{CeO}_{2}$ precursor was pressed into an inert metal mesh and mounted on a sample holder that was specially designed for the IR transmission measurements. The $\mathrm{CuO} / \mathrm{CeO}_{2}$ sample was pretreated with $\mathrm{O}_{2}$ at $573 \mathrm{~K}$ for $1 \mathrm{~h}$, and reduced by $\mathrm{H}_{2}$ at $473-773 \mathrm{~K}$, resulting in the $\mathrm{CU}-\mathrm{T}$ catalysts. Exposure to $\mathrm{CO}, \mathrm{O}_{2}$ and $\mathrm{D}_{2} \mathrm{O}$ at desired temperatures was achieved using a leak-valve-based directional doser. The IR data were accumulated by recording 1024 scans with a resolution of $4 \mathrm{~cm}^{-1}$.

XPS analysis. The XPS data were recorded on an Omicron Sphera II hemispherical XPS instrument using a monochromatic Al $\mathrm{K} \alpha$ source. The $\mathrm{CuO} / \mathrm{CeO}_{2}$ precursor was pressed into a thin disc, mounted onto a sample rod, and reduced with a 5.0 vol. $\% \mathrm{H}_{2} / \mathrm{Ar}\left(30 \mathrm{~mL} \mathrm{~min}{ }^{-1}\right)$ mixture at 473-773 K for $2 \mathrm{~h}$ at the pretreatment chamber. XPS of Cu2p, CuL3VV, Ce3d, and O1s in the resulting $\mathrm{Cu}$-T catalysts were recorded in the analysis chamber. Charging effect was corrected by adjusting the binding energy of Ce3d (v) to $882.5 \mathrm{eV}$.

DFT calculations. The ab-initio calculations were based on the DFT within the Perdew-BurkeErnzerhof (PBE) generalized exchange and correlation energy functional. The spin-polarized 
Kohn-Sham equations were solved in the plane-wave (ultra soft) pseudo-potential approach. The plane-wave basis sets for the electron wave function and the augmentation charge density were limited by energy cut-off of 30 Ry and 300 Ry, respectively. All calculations involved the addition of a Hubbard $\mathrm{U}(4.5 \mathrm{eV})$ term to the PBE energy functional $(\mathrm{PBE}+\mathrm{U})$. The copper-ceria interface was modelled with a periodic supercell slabs consisting of a Cu bilayer supported on a reduced 9-layer thick ceria substrate. Additional computational details are reported in the Supplementary Methods.

Catalytic test. The low-temperature water-gas shift reaction was performed with a continuousflow fixed-bed quartz tubular reactor (6 mm, inner diameter) under atmospheric pressure. 100 $\mathrm{mg} \mathrm{CuO} / \mathrm{CeO}_{2}$ precursor (40-60 mesh) was loaded into the reactor, pretreated with a 20.0 vol.\% $\mathrm{O}_{2} / \mathrm{N}_{2}$ mixture $\left(30 \mathrm{~mL} \mathrm{~min}^{-1}\right)$ at $573 \mathrm{~K}$ for $1 \mathrm{~h}$, reduced with a 2.0 vol.\% $\mathrm{H}_{2} / \mathrm{Ar}$ mixture $\left(30 \mathrm{~mL} \mathrm{~min}^{-1}\right.$ ) at the desired temperatures (473-773 K) for $2 \mathrm{~h}$. The reaction was then tested at $473 \mathrm{~K}$ with a feed gas of 1.0 vol.\% $\mathrm{CO} / 3.0$ vol.\% $\mathrm{H}_{2} \mathrm{O} / \mathrm{He}\left(67 \mathrm{~mL} \mathrm{~min}^{-1}\right)$ for about $10 \mathrm{~h}$. The effluent from the reactor was analyzed online with a gas chromatography equipped with a thermal conductivity detector and a flame ionization detector. The reaction rate was measured at a differential reactor condition, under which the conversion of CO was adjusted to be around $10 \%$ by varying the flow rate of the reaction gas or the weight of the catalyst.

\section{Data availability}

The data that support the plots within this paper and other findings of this study are available from the corresponding author upon reasonable request. 


\section{References}

1. Li, Y., Fu, Q. \& Flytzani-Stephanopoulos, M. Low-temperature water-gas shift reaction over Cuand Ni-loaded cerium oxide catalysts. Appl. Catal. B: Environ. 27, 179-191 (2000).

2. Wang, X. et al. In situ studies of the active sites for the water gas shift reaction over $\mathrm{Cu}-\mathrm{CeO}_{2}$ catalysts: complex interaction between metallic copper and oxygen vacancies of ceria. J. Phys. Chem. B 110, 428-434 (2006).

3. Gawade, P., Mirkelamoglu, B. \& Ozkan, U. S. The role of support morphology and impregnation medium on the water gas shift activity of ceria-supported copper catalysts. J. Phys. Chem. C 114, 18173-18181 (2010).

4. $\mathrm{Si}, \mathrm{R}$. et al. Structure sensitivity of the low-temperature water-gas shift reaction on $\mathrm{Cu}-\mathrm{CeO}_{2}$ catalysts. Catal. Today 180, 68-80 (2012).

5. Yao, S. et al. Morphological effects of the nanostructured ceria support on the activity and stability of $\mathrm{CuO} / \mathrm{CeO}_{2}$ catalysts for the water-gas shift reaction. Phys. Chem. Chem. Phys. 16, 17183-17195 (2014).

6. Ren, Z., Peng, F., Li, J., Liang, X. \& Chen, B. Morphology-dependent properties of $\mathrm{Cu} / \mathrm{CeO}_{2}$ catalysts for the water-gas shift reaction. Catalysts 7, 48-60 (2017).

7. Chen, $\mathrm{C}$. et al. $\mathrm{Cu} / \mathrm{CeO}_{2}$ catalyst for water-gas shift reaction: effect of $\mathrm{CeO}_{2}$ pretreatment. ChemPhyChem 19, 1448-1455 (2018).

8. Shen, W., Ichihashi, Y. \& Matsumura, Y. Low-temperature methanol synthesis from carbon monoxide and hydrogen over ceria supported copper catalyst. Appl. Catal. A: Gen. 282, 221-226 (2005).

9. Yang, R. et al. Performance of Cu-based catalysts in low-temperature methanol synthesis. Adv. Mater. Res. 1004-1005, 1623-1626 (2014).

10. Graciani, J. et al. Highly active copper-ceria and copper-ceria-titania catalysts for methanol synthesis from $\mathrm{CO}_{2}$. Science $345,546-551$ (2014).

11. Rodriguez, J. A. et al. Hydrogenation of $\mathrm{CO}_{2}$ to methanol: importance of metal-oxide and metal-carbide interfaces in the activation of $\mathrm{CO}_{2}$. ACS Catal. 5, 6696-6706 (2015).

12. Ouyang, B., Tan, W. \& Li, B. Morphology effect of nanostructure ceria on the $\mathrm{Cu} / \mathrm{CeO}_{2}$ catalysts for synthesis of methanol from $\mathrm{CO}_{2}$ hydrogenation. Catal. Comm. 95, 36-39 (2017). 
13. van de Water, L. G. A., Wilkinson, S. K., Smith, R. A. P. \& Watson, M. J. Understanding methanol synthesis from $\mathrm{CO} / \mathrm{H}_{2}$ feeds over $\mathrm{Cu} / \mathrm{CeO}_{2}$ catalysts. J. Catal. 364, 57-68 (2018).

14. Konsolakis, M. The role of copper-ceria interactions in catalysis science: recent theoretical and experimental advances. Appl. Catal. B: Environ. 198, 49-66 (2016).

15. Trovarelli, A. \& Llorca, J. Ceria catalysts at nanoscale: how do crystal shapes shape catalysis? ACS Catal. 7, 4716-4735 (2017).

16. Rodriguez, J. A., Grinter, D. C., Liu, Z., Palomino, R. M. \& Senanayake, S. D. Ceria-based model catalysts: fundamental studies on the importance of the metal-ceria interface in CO oxidation, the water-gas shift, $\mathrm{CO}_{2}$ hydrogenation, and methane and alcohol reforming. Chem. Soc. Rev. 46, 1824-1841 (2017).

17. Mudiyanselage, K. et al. Importance of the metal-oxide interface in catalysis: in situ studies of the water-gas shift reaction by ambient-pressure X-ray photoelectron spectroscopy. Angew. Chem. Int. Ed. 52, 5101-5105 (2013).

18. Senanayake, S. D., Stacchiola D. \& Rodriguez, J. A. Unique properties of ceria nanoparticles supported on metals: novel inverse ceria/copper catalysts for CO oxidation and the water-gas shift reaction. Acc. Chem. Res. 46, 1702-1711 (2013).

19. Szabová, L., Camellone, M. F., Huang, M., Matolín, V. \& Fabris S. Thermodynamic, electronic and structural properties of $\mathrm{Cu} / \mathrm{CeO}_{2}$ surfaces and interfaces from first-principles $\mathrm{DFT}+\mathrm{U}$ calculations. J. Chem. Phys. 133, 234705 (2010).

20. Yang, Z., Xie, L., Ma, D. \& Wang, G. Origin of the high activity of the ceria-supported copper catalyst for $\mathrm{H}_{2} \mathrm{O}$ dissociation. J. Phys. Chem. C 115, 6730-6740 (2011).

21. James, T. E., Hemmingson, S. L., Ito, T. \& Campbell, C. T. Energetics of Cu adsorption and adhesion onto reduced $\mathrm{CeO}_{2}(111)$ surfaces by calorimetry. J. Phys. Chem. C 119, 17209-17217 (2015).

22. James, T. E., Hemmingson, S. L. \& Campbell, C. T. Energy of supported metal catalysts: from single atoms to large metal nanoparticles. ACS Catal. 5, 5673-5678 (2015).

23. Chutia, A. et al. The adsorption of $\mathrm{Cu}$ on the $\mathrm{CeO}_{2}(110)$ surface, Phys. Chem. Chem. Phys. 19, 27191-27203 (2017).

24. Si, R. \& Flytzani-Stephanopoulos, M. Shape and crystal-plane effects of nanoscale ceria on the 
activity of $\mathrm{Au}-\mathrm{CeO}_{2}$ catalysts for the water-gas shift reaction. Angew. Chem. Int. Ed. 47, 28842887 (2008).

25. Farmer, J. A. \& Campbell, C. T. Ceria maintains smaller metal catalyst particles by strong metalsupport bonding. Science 329, 933-936 (2010).

26. Yamada, Y. et al. Nanocrystal bilayer for tandem catalysis. Nat. Chem. 3, 372-376 (2011).

27. Yoshida, H. et al. Visualizing gas molecules interacting with supported nanoparticulate catalysts at reaction conditions. Science 335, 317-319 (2012).

28. Cargnello, M. et al. Control of metal nanocrystal size reveals metal-support interface role for

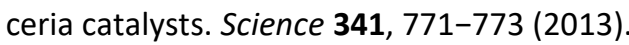

29. Lin, Y. et al. Adhesion and atomic structures of gold on ceria nanostructures: the role of surface structure and oxidation state of ceria supports. Nano Lett. 15, 5375-5381 (2015).

30. Gänzler, A. M. et al. Tuning the $\mathrm{Pt} / \mathrm{CeO}_{2}$ interface by in situ variation of the Pt particle size. ACS Catal. 8, 4800-4811 (2018).

31. Chen, A., Zhou, Y., Ta, N., Li, Y. \& Shen, W. Redox properties and catalytic performance of ceriazirconia nanorods. Catal. Sci. Technol. 5, 4184-4192 (2015).

32 Tang, X. et al. $\mathrm{CuO} / \mathrm{CeO}_{2}$ catalysts: redox features and catalytic behaviors. Appl. Catal. A: Gen. 288, 116-125 (2005).

33. Wang, W. et al. Crystal plane effect of ceria on supported copper oxide cluster catalyst for CO oxidation: importance of metal-support Interaction. ACS Catal. 7, 1313-1329 (2017).

34. $\mathrm{Wu}$, L. et al. Oxidation state and lattice expansion of $\mathrm{CeO}_{2-x}$ nanoparticles as a function of particle size. Phys. Rev. B 69, 125415 (2004).

35. Keast, V. J., Scott, A. J., Brydson R., Williams, D. B. \& Bruley, J. Electron energy-loss near-edge structure-a tool for the investigation of electronic structure on the nanometre scale. J. Microsc. 203, 135-175 (2001).

36. Wagner, J. B. et al. In situ electron energy loss spectroscopy studies of gas-dependent metalsupport interactions in Cu/ZnO catalysts. J. Phys. Chem. B 107, 7753-7758 (2003).

37. Wang, Y. \& Wöll, C. IR spectroscopic investigations of chemical and photochemical reactions on metal oxides: bridging the materials gap. Chem. Soc. Rev. 46, 1875-1932 (2017).

38. Yang, C. et al. Chemical activity of oxygen vacancies on ceria: a combined experimental and 
theoretical study on $\mathrm{CeO}_{2}$ (111). Phys. Chem. Chem. Phys. 16, 24165-24168 (2014).

39. Yang, C. et al. Surface faceting and reconstruction of ceria nanoparticles. Angew. Chem. Int. Ed. 56, 375-379 (2017).

40. Cox, D. F. \& Schulz, K. H. Interaction of $\mathrm{CO}$ with $\mathrm{Cu}^{+}$cations: $\mathrm{CO}$ adsorption on $\mathrm{Cu}_{2} \mathrm{O}(100)$. Surf. Sci. 249, 138-148 (1991).

41. Martínez-Arias, A., Fernández-García, M., Soria, J. \& Conesa, J. C. Spectroscopic study of a $\mathrm{Cu} / \mathrm{CeO}_{2}$ catalyst subjected to redox treatments in carbon monoxide and oxygen. J. Catal. 182, 367-377 (1999).

42. Vollmer, S., Witte, G. \& Wöll, C. Determination of site specific adsorption energies of CO on copper. Catal. Lett. 77, 97-101 (2001).

43. Chen, S. et al. Anchoring high-concentration oxygen vacancies at interfaces of $\mathrm{CeO}_{2-\mathrm{x}} / \mathrm{Cu}$ toward enhanced activity for preferential CO oxidation. ACS Appl. Mater. Interfaces 7, 22999-23007 (2015)

44. Fabris, S., Vicario, G., Balducci, G., de Gironcoli, S. \& Baroni S. Electronic and atomistic structures of clean and reduced ceria surfaces. J. Phys. Chem. B 109, 22860-22867 (2005).

45. Lykhach, Y. et al. Counting electrons on supported nanoparticles, Nat. Mater. 15, 284-288 (2016).

46. Branda, M. M., Hernández, N. C., Sanz, J. F. \& Illas, F. Density functional theory study of the interaction of $\mathrm{Cu}, \mathrm{Ag}$, and $\mathrm{Au}$ atoms with the regular $\mathrm{CeO}_{2}$ (111) surface. J. Phys. Chem. C 114, 1934-1941(2010).

47. Figueroba, A., Kovács, G., Bruix, A., Neyman, K. M. Towards stable single-atom catalysts: strong binding of atomically dispersed transition metals on the surface of nanostructured ceria, Catal. Sci. Technol. 6, 6806-6813 (2016).

48. $\mathrm{Li}$, L. et al. Water-gas shift reaction over $\mathrm{CuO} / \mathrm{CeO}_{2}$ catalysts: effect of the thermal stability and oxygen vacancies of $\mathrm{CeO}_{2}$ supports previously prepared by different methods. Catal. Lett. 130, 532-540 (2009).

49. López. Cámara, A., Chansai, S., Hardacre, C. \& Martínez-Arias, A. The water-gas shift reaction over $\mathrm{CeO}_{2} / \mathrm{CuO}$ : operando SSITKA-DRIFTS-mass spectrometry study of low temperature mechanism. Inter. J. Hydrogen Energy 39, 4095-4101 (2014). 
50. Caldas, P. C. P., Gallo, J. M. R., Lopez-Castillo, A., Zanchet, D. \& Bueno, J. M. C. The structure of the $\mathrm{Cu}-\mathrm{CuO}$ sites determines the catalytic activity of Cu nanoparticles. ACS Catal. 7, 2419-2424 (2017).

\section{Acknowledgements}

This work is supported by the National Natural Science Foundation of China (91645107, 21533009, 21621063, 21761132031), the Deutsche Forschungsgemeinschaft (WA 2535/2-1), and the "Science and Technology of Nanosystems" Programme (432202) of Germany. X.Y. and C.Y. thank the PhD fellowships sponsored by the China Scholarship Council. We acknowledge support from the EU-H2020 research and innovation programme under Grant Agreement No. 654360 NFFA-Europe.

\section{Author contributions}

A.C., J.N., C.J. and Y.L. prepared the catalysts and conducted the reaction tests. X.Y., C.Y., A.N., C.W. and Y.W. performed UHV-IR analysis. S.K. and J.S. performed chemical titrations and reaction tests. Y.Z., S.M., J.L., T.A. and S.H. conducted STEM and EELS analysis. M.F.C. and S.F. performed DFT calculations on the interfacial structure. S.F. and C.W. contributed to deep discussions on this work. Y.Z., J.S., Y.W. and W.S. designed the experiments, analyzed the data and wrote the paper.

\section{Additional information}

Supplementray Information is available at the online version of the paper. Reprints and permissions information is available at www.nature.com/reprinpts. Correspondence and requests fo materials should be addressed to Y.Z., J.S., Y.W. or W.S.

\section{Competing financial interests}

The authors declare no competing financial interests. 

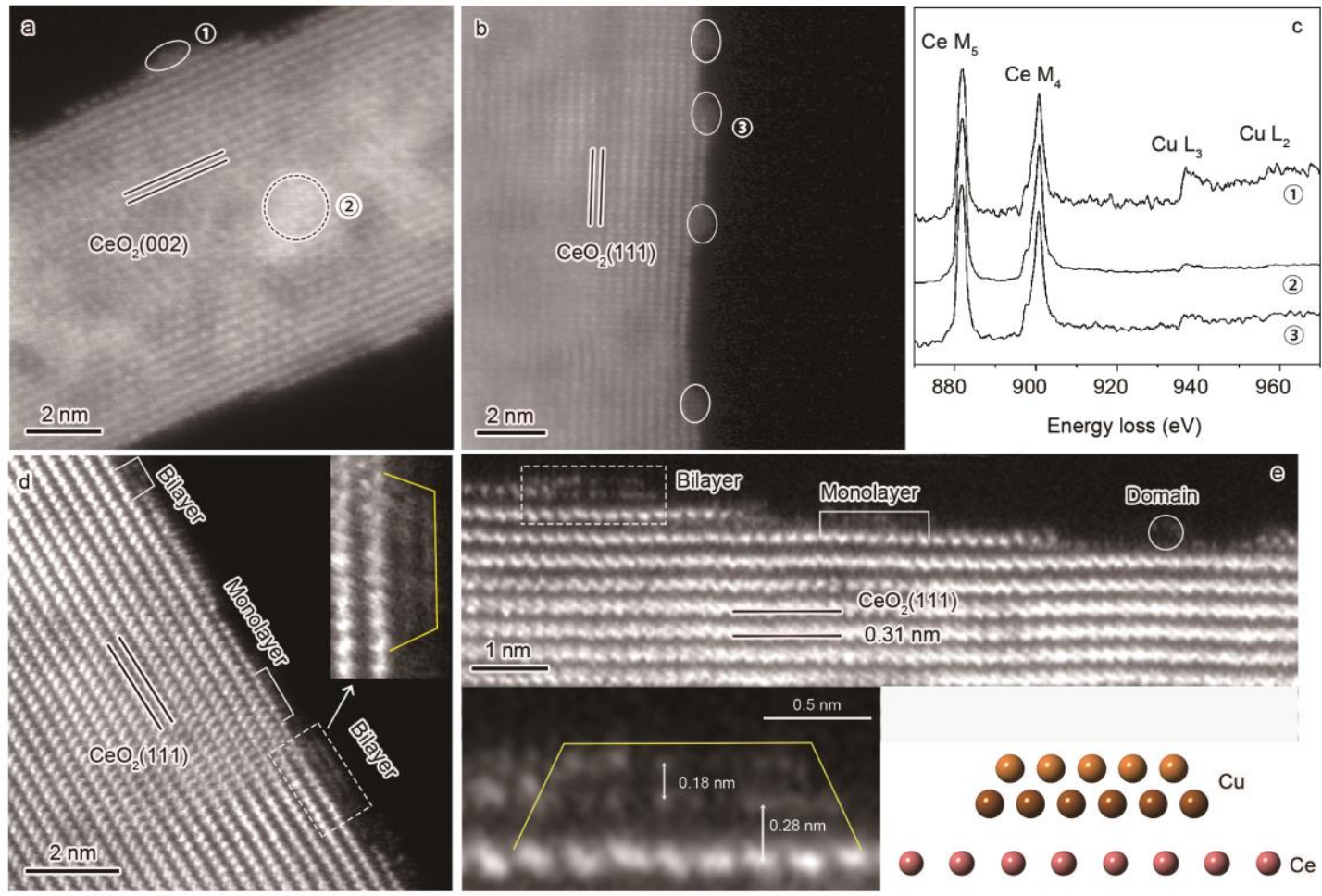

Fig. 1 | Identification of copper clusters on ceria in the Cu-473 catalyst. a,b, HAADF-STEM images of Cu clusters on the (100) and (111) facets of ceria rods; c, EELS of the copper clusters marked with circles (1),(2),(3) in $\mathbf{a}$ and $\mathbf{b}$, affirming the copper clusters anchored on ceria rods. $\mathbf{d}, \mathbf{e}$, Atom-resolved HAADF-STEM images of copper clusters on ceria rods, showing the atomic configurations of copper domains, monolayers and bilayers; the inset in $\mathbf{d}$ is an enlarged image of a copper bilayer in the rectangular region; the bottom of e shows the enlarged image of a typical copper bilayer (marked in the rectangular area) and the corresponding geometric arrangement of copper and cerium atoms at the interface. 

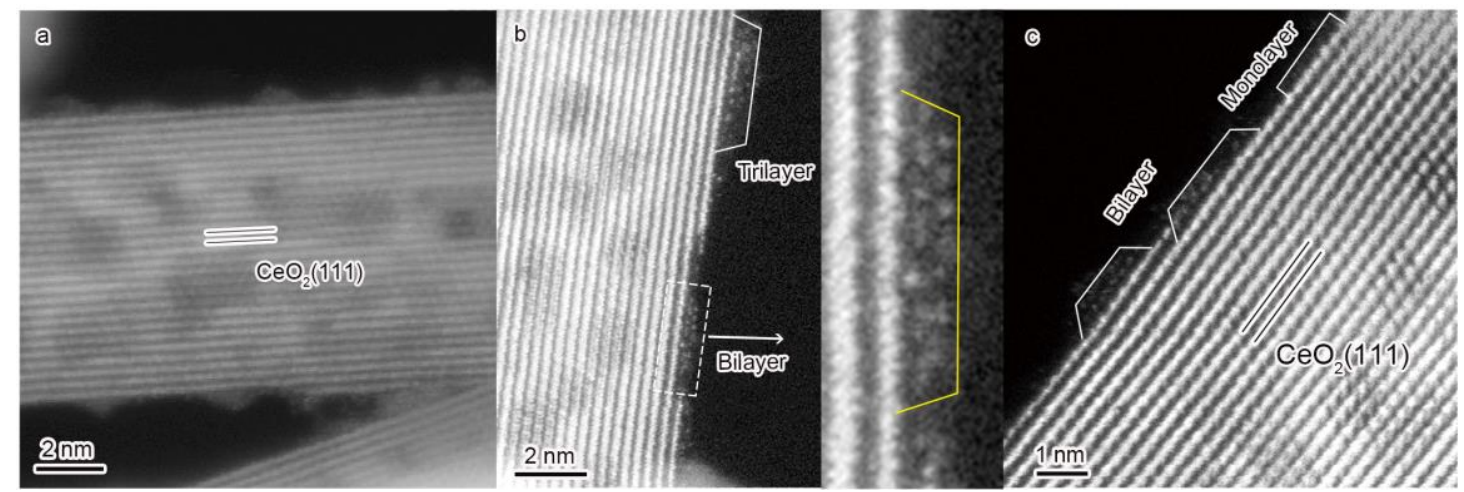

Fig. 2 | Geometric structures of copper clusters on ceria in the Cu-773 catalyst. a, A HAADF-STEM image of copper clusters dispersed on a ceria rod. b,c, Atom- resolved HAADF-STEM images of copper clusters on ceria rods; the inset in $\mathbf{b}$ is an enlarged image of a selected bilayer, showing the arrangements of copper atoms within the copper cluster and at the copper-ceria interface. 

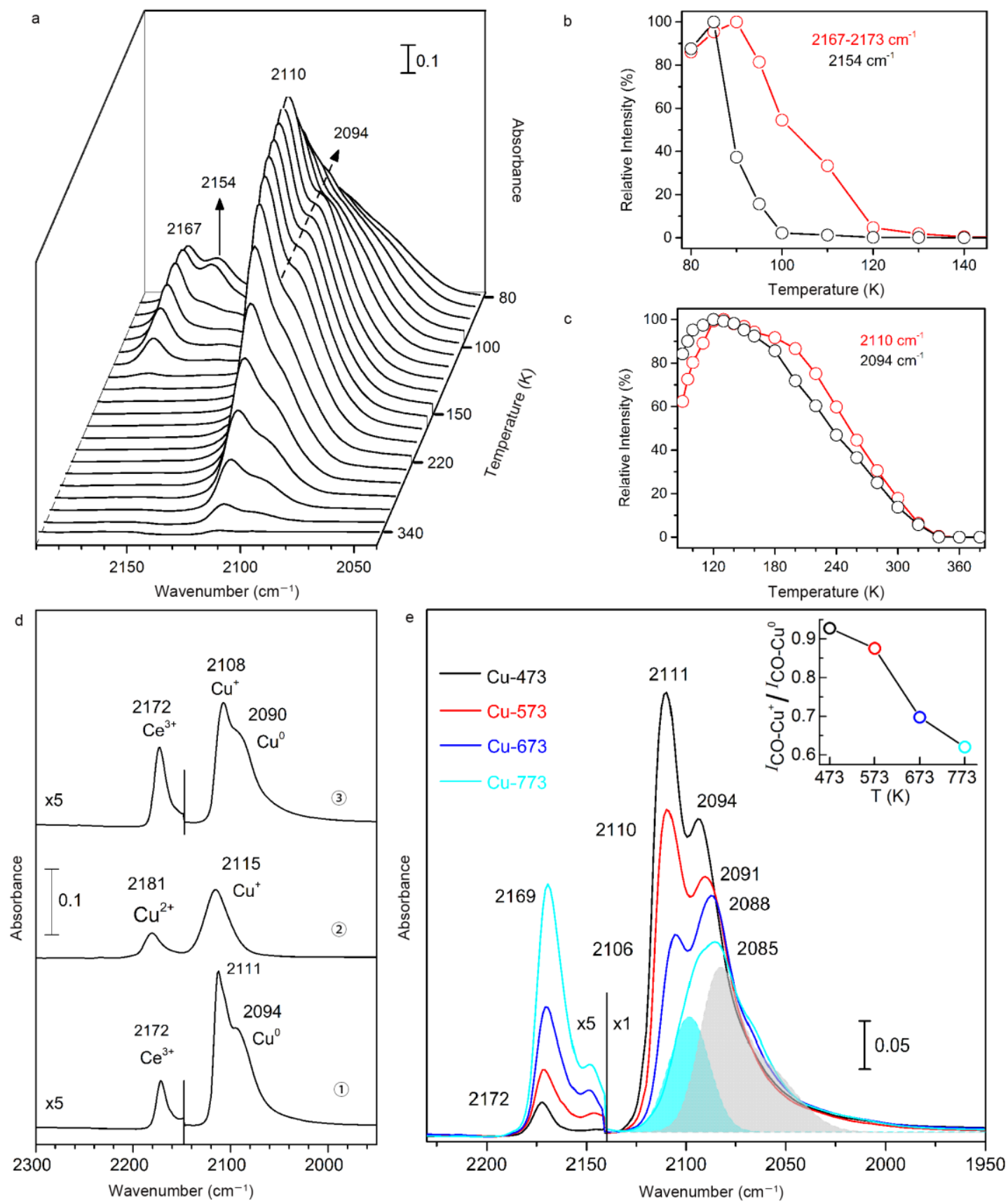

Fig. 3 | Binding environment of the copper-ceria interface probed by in situ IR spectroscopy. a, Temperature-dependent IR spectra recorded after exposing the $\mathrm{Cu}-473$ sample to $\mathrm{CO}$ (0.01 mbar) at $80 \mathrm{~K}$ and subsequently heating up to $340 \mathrm{~K}$. b,c, Intensity evolution of the IR bands resulting from CO bound to surface $\mathrm{Ce}^{4+}$ and defect (mainly $-\mathrm{Ce}^{3+}-\mathrm{O}_{\mathrm{v}}$ ) sites (b) and to $\mathrm{Cu}^{0}$ and $\mathrm{Cu}^{+}$sites (c) as a function of temperature. $\mathbf{d}$, Dynamic variations in $\mathrm{Cu}^{0}$ and $\mathrm{Cu}^{+}$sites obtained after $\mathrm{CO}$ adsorption at $110 \mathrm{~K}$ over the Cu-473 sample that was pretreated under alternating reductive and oxidative conditions: (1) reduction with hydrogen at $473 \mathrm{~K}$; (2) re-oxidation with oxygen at $110 \mathrm{~K}\left(0.01 \mathrm{mbar} \mathrm{O}_{2}\right)$; (3) subsequent reduction 
with hydrogen at $473 \mathrm{~K}$. e, IR spectra obtained after $\mathrm{CO}$ adsorption on the $\mathrm{Cu}-\mathrm{T}$ samples at $110 \mathrm{~K}$; the upright inset shows the decreasing intensity (peak area) ratio of $\mathrm{Cu}^{+}$-related to $\mathrm{Cu}^{0}$-related $\mathrm{CO}$ bands as increasing the temperature for hydrogen pretreatment; the cyan and grey areas in the $\mathrm{Cu}-773$ sample refer to the $\mathrm{Cu}^{+}$- and $\mathrm{Cu}^{0}$-related $\mathrm{CO}$ bands, respectively. $\mathrm{Note}$, all $\mathrm{Cu}^{0} / \mathrm{Cu}^{+}$-related $\mathrm{CO}$ bands had a red-shift to lower frequencies as increasing the temperature for hydrogen pretreatment, which could be attributed to the electronic modification of the copper species.

a

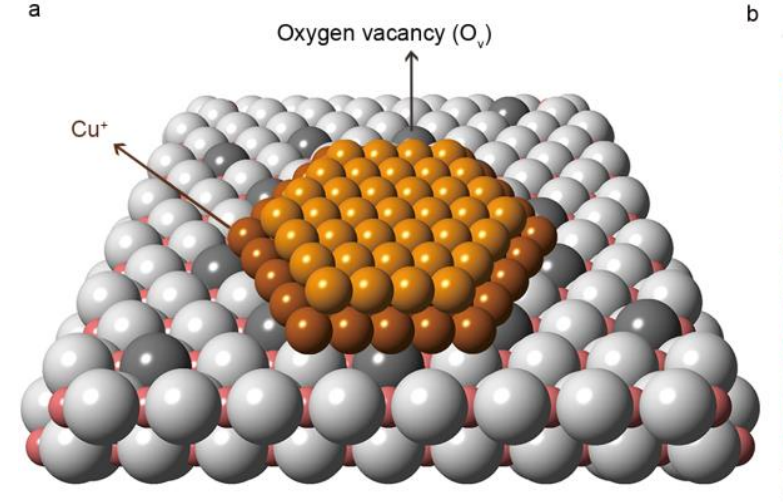

- $\mathrm{Cu}$

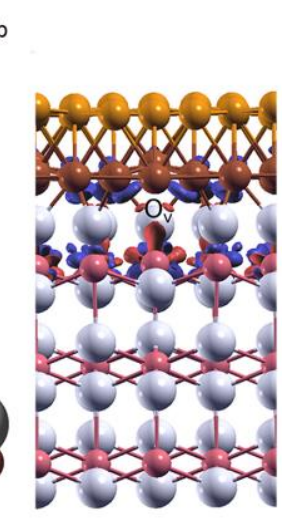

$0 \bigcirc \mathrm{Ce}$

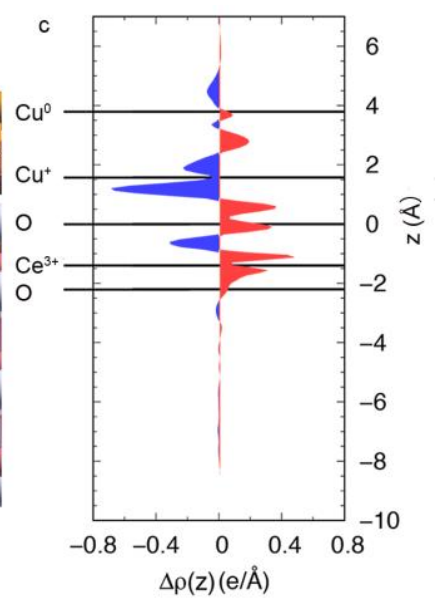

Fig. 4 | Atomic structure of the copper-ceria interfacial perimeter. a, A schematic illustration of the typical $\mathrm{Cu}$ bilayer on ceria. $\mathbf{b}$, Calculated equilibrium structure and charge transfer between the $\mathrm{Cu}$ bilayer and the reduced ceria surface in a periodic supercell. c, Plane-integrated bonding charge $\Delta \rho(z)$ as a function of position across the copper-ceria interface. The red and blue areas represent charge accumulation and depletion, respectively. 

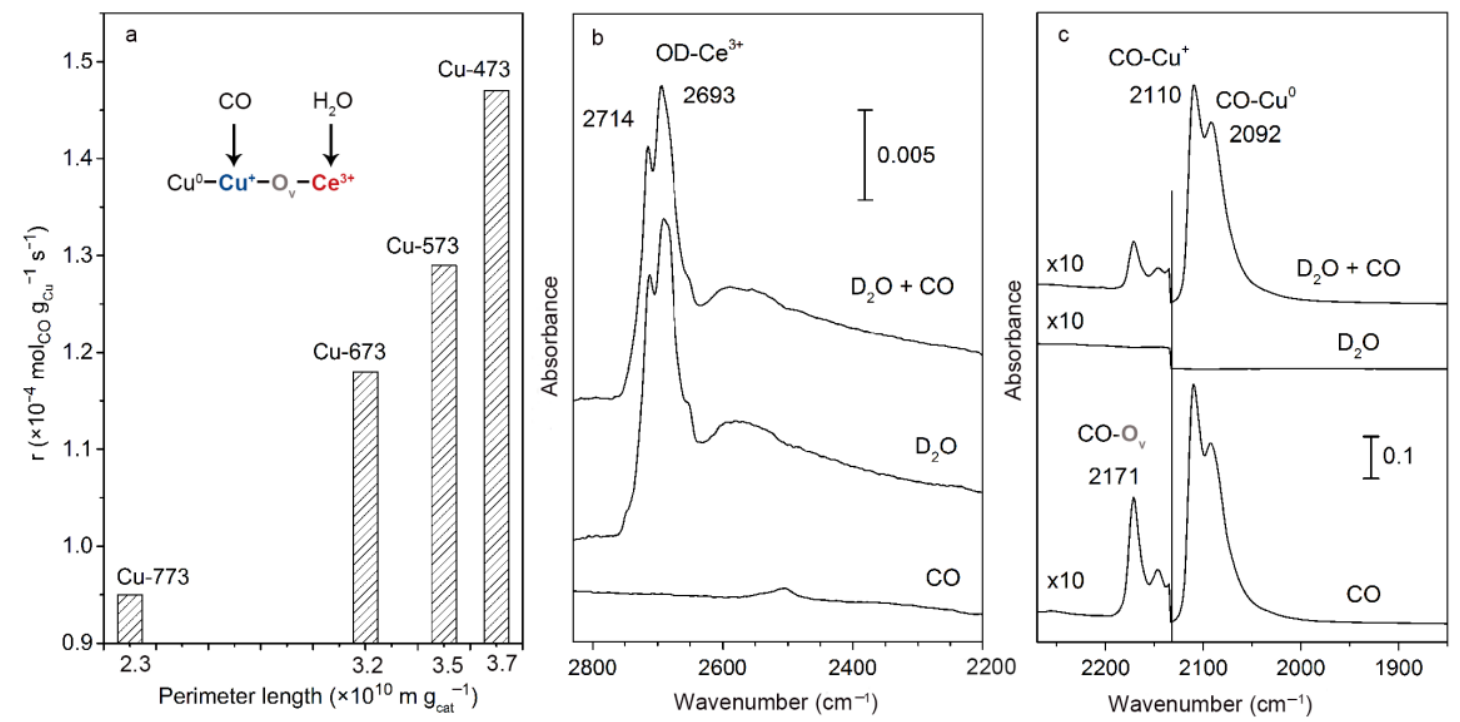

Fig. 5 Water-gas shift reaction over the Cu-T catalysts. a, The reaction rates of WGS at $473 \mathrm{~K}$ as a function of the total length of the copper-ceria interfacial perimeter and the atomic illustration (insert) of the cooperative mechanism of the active sites for the activation of $\mathrm{CO}$ and $\mathrm{H}_{2} \mathrm{O}$ molecules. $\mathbf{b}, \mathbf{c}$, The $\mathrm{OD} / \mathrm{D}_{2} \mathrm{O}$ region (b) and the $\mathrm{CO}$ region (c) of UHV-IR spectra obtained by exposing the $\mathrm{Cu}-473$ catalyst to $C O$ at $110 \mathrm{~K}$, water $\left(D_{2} \mathrm{O}\right)$ at $250 \mathrm{~K}$, and first $\mathrm{D}_{2} \mathrm{O}$ at $250 \mathrm{~K}$ and then $\mathrm{CO}$ at $110 \mathrm{~K}$, respectively, evidencing that the $\mathrm{Cu}^{+}$site chemically adsorbs $\mathrm{CO}$ while the $-\mathrm{O}_{\mathrm{v}}-\mathrm{Ce}^{3+}$ - site dissociatively activates $\mathrm{D}_{2} \mathrm{O}$. 
TOC Graphic:

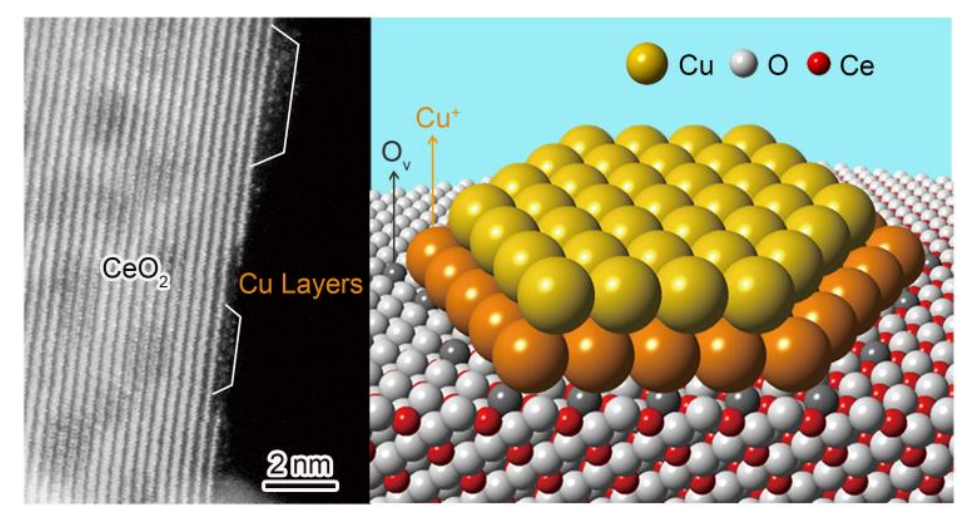

\section{Editor's summary}

Copper on ceria is an excellent catalyst for the low-temperature water-gas shift reaction. Here the active sites are directly imaged by electron microscopy and probed with in-situ spectroscopy, showing that the reaction proceeds via a cooperative mechanism whereby the $\mathrm{Cu}^{+}$chemically adsorbs $\mathrm{CO}$ while an adjacent $\mathrm{O}-\mathrm{Ce}^{3+}$ site dissociatively activates $\mathrm{H}_{2} \mathrm{O}$. 